\title{
Thrombin to Antithrombin Ratio Measurement
}

National Cancer Institute

\section{Source}

National Cancer Institute. Thrombin to Antithrombin Ratio Measurement. NCI

Thesaurus. Code C106574.

The determination of the ratio of thrombin compared to antithrombin present in a sample. The measurement may be expressed as a ratio or percentage. 